\title{
Valuation of the Economic Benefits from Using Genetically Improved Forest Reproductive Materials in Afforestation
}

\author{
Nicu Marcu ${ }^{1,2}$, Marius Budeanu ${ }^{3, *}$, Ecaterina Nicoleta Apostol ${ }^{4}$ and Raul Gheorghe Radu ${ }^{3}$ \\ 1 Academy of Economic Studies, 6 Piaţa Romană street, 010374 Bucharest, Romania; marcu.nicu@yahoo.com \\ 2 Institute of National Economy-Romanian Academy, 13 Septembrie street, 050731 Bucharest, Romania \\ 3 National Institute for Research and Development in Forestry "Marin Drăcea", Braşov Research Station, \\ 13 Cloşca street, 500040 Braşov, Romania; raul.radu@icas.ro \\ 4 National Institute for Research and Development in Forestry "Marin Drăcea", Voluntari, 128 Eroilor Blvd., \\ 077190 Ilfov, Romania; ecaterina.apostol@icas.ro \\ * Correspondence: marius.budeanu@icas.ro; Tel.: +40-726-009-162
}

Received: 6 March 2020; Accepted: 25 March 2020; Published: 27 March 2020

\begin{abstract}
The research objective was to demonstrate the economic impact of using, in afforestation, forest reproductive materials (FRMs) obtained from seed trees selected in the most valuable Norway spruce populations of the FGRs' (forest genetic resources') category. The values obtained for the main growth traits (diameter at breast height (Dbh), tree height (Th), and tree volume (Tv)), both in the FGR and in the closest population (with the same age and growth in similar environmental conditions), were compared. Three comparative trials were analyzed, each belonging to different breeding levels: Open-pollinated (Brețcu, 40 years old), half-sib (Măneciu, 25 years), and full-sib (Comandău, 23 years). The difference in volume/hectare between the FGR and an unimproved neighbor population was economically quantified $(€)$, based on the average price per cubic meter $\left(\mathrm{m}^{3}\right)$ of spruce wood in Romania; the profit at the end of the rotation period (110 years) was projected taking into account the genetic gain that will result from the use of FRM collected from the FGRs. The average FGR growth results were superior to the unimproved neighbor populations, with $8 \%-13 \%, 14 \%-25 \%$, and $26 \%-79 \%$ for Dbh, Th, and volume/ha, respectively, and the differences increased if the best $10 \%$ seed trees of the trials were used. For Th, a five times higher family mean heritability was registered for the pendula trees (compared to pyramidalis) in the half-sib trial, while in the full-sib experiment, the pendula trees (both full and half pendula) again registered higher heritability, but for Dbh, which recommends the pendula selection for different traits in the two trials. These results have led to a rate of profitability between 540 and $3366 € /$ ha, a value that is predicted to increase until the end of the rotation period, when the genetic gain could generate a profit of $7560 € /$ ha.
\end{abstract}

Keywords: biodiversity; breeding strategy; economic analysis; forest values; genetic gain; heritability

\section{Introduction}

Forest ecosystems, managed properly, offer important resources for direct economic goods (e.g., timber) [1], additional wooden products, numerous nontimber forest products (fruits, oils, medicinal plants, etc.), and support other economic activities, for instance, agriculture and fisheries [2]. The relationship between forest ecosystems and the forest industry requires a balance between the needs of industry and the development of natural ecosystems [3]. The continuously increasing demand for wood requires the identification of solutions to increase the production of wood/ha. This could be achieved, among other methods, by using genetically improved forest reproductive material (FRM) in plantations [4-6]. Additionally, increasingly climatic disturbances affect trees' resistance and 
their physiological processes [7]. The selection of an adapted population and seed trees inside them represents a chance to increase forest stability and productivity over the next generations of breeding programs by using FRM from these populations [8-15]. In the last 100 years, artificial regeneration has continually increased [16,17] and numerous allochthonous species have been used [18-23].

Identification, conservation, and management strategies for forest genetic resources (FGRs) are of high interest for geneticists [24]. The conservation of FGRs is important for maintaining genetic diversity in large populations (minimum 500 seed trees/population), preserving specific adaptations in marginal/peripheral populations (minimum 50 seed trees/population), and conserving rare species in relict populations (minimum 15 seed trees/population) [25]. The dynamic FGR conservation strategy [24] was implemented in Romania, as well as 32 other European countries. As sequencing of the Norway spruce genome is complete [26], the genomic selection can be combined with traditional breeding programs, constituting a giant leap in tree breeding $[27,28]$.

The objective of the present paper was to demonstrate the economic importance of using, in afforestation, the FRM obtained from seed trees selected in the most valuable populations, within the FGR's category. For a very important species of the Romanian [29] and European forests [30,31], Norway spruce (Picea abies), we compared the values obtained for the main growth traits (diameter at breast height (Dbh), tree height (Th), and tree volume (Tv)) both in the FGR, and in the closest unimproved population with approximately the same age and benefiting from similar environmental conditions. Additionally, the average values recorded in the FGR were compared to the average values at the country level. Differences in trees volume/hectare between FGRs and the closest unimproved populations were transformed into euros $(€)$, taking into account the average price per cubic meter $\left(\mathrm{m}^{3}\right)$ of spruce wood in Romania. Additionally, the profit at the end of the rotation period (110 years) was projected based on the genetic gain that would result from the use of FRM collected from the FGRs.

\section{Materials and Methods}

Three comparative trials from different breeding levels were investigated: One open-pollinated (Breţcu, 40 years), one half-sib (Măneciu, 25 years), and one full-sib (Comandău, 23 years). Data for the nearest similar stands (same ages and similar environmental conditions) were also taken.

The Breţcu trial was established in the ecological optimum for Norway spruce, in the Curvature Carpathians region (i.e., the inner zone of the Carpathian chain), at a 1100-m average altitude (a.s.1.), at $45^{\circ} 58^{\prime} \mathrm{N}$ latitude and $26^{\circ} 24^{\prime} \mathrm{E}$ longitude, in a mountainous mixed-stand vegetation forest. The slope has a northeast exposition with a $15^{\circ}$ inclination. The soil is typical eutricambosoil. The average annual temperature was $4.8^{\circ} \mathrm{C}$, and the sum of the annual precipitation was $830 \mathrm{~mm}$ [32]. In this trial, 33 seed stand provenances (Figure 1) were tested in an incomplete balanced square-grid design, with three replications and 49 seedlings/plot, planted with $2 \mathrm{~m}$ by $2 \mathrm{~m}$ spacing. Every provenance was composed of progenies obtained from bulked seeds harvested from 10 trees [33]. In each replication, 10 trees/provenance were randomly chosen and the diameter at breast height (Dbh) and tree height (Th) were measured. At the office, tree volume (Tv) was determined using the volume regression equation method [34].

The Măneciu comparative trial was also located in the Curvature Carpathians, but on the outside zone of the Carpathian chain, in a superior productivity forest type. The soil is also typical eutricambosoil, but on a slope with southern exposition, $10^{\circ}$ inclination, at an altitude of $820 \mathrm{~m}$, $45^{\circ} 25^{\prime} \mathrm{N}$ latitude and $25^{\circ} 57^{\prime} \mathrm{E}$ longitude. The average annual temperature here is $6.0^{\circ} \mathrm{C}$, and the sum of the annual precipitation is $880 \mathrm{~mm}$. In this trial, the experimental design was incompletely balanced, with four replications and 4-10 seedlings per plot planted with $2 \mathrm{~m}$ by $2 \mathrm{~m}$ spacing, in which each of the eight provenances (yellow circles, in Figure 1) were represented by descendants obtained from seeds harvested from three pendula and three normal crown spruce trees, resulting in a total number of 24 families for each of the two crown forms [35]. The Măneciu trial was installed in order to test the behavior of the narrow-crown Norway spruce ideotype (pendula form), which was believed to be 
stronger than the normal spruce crown (pyramidalis variety) in the face of harmful action of storms and heavy snows [36,37].

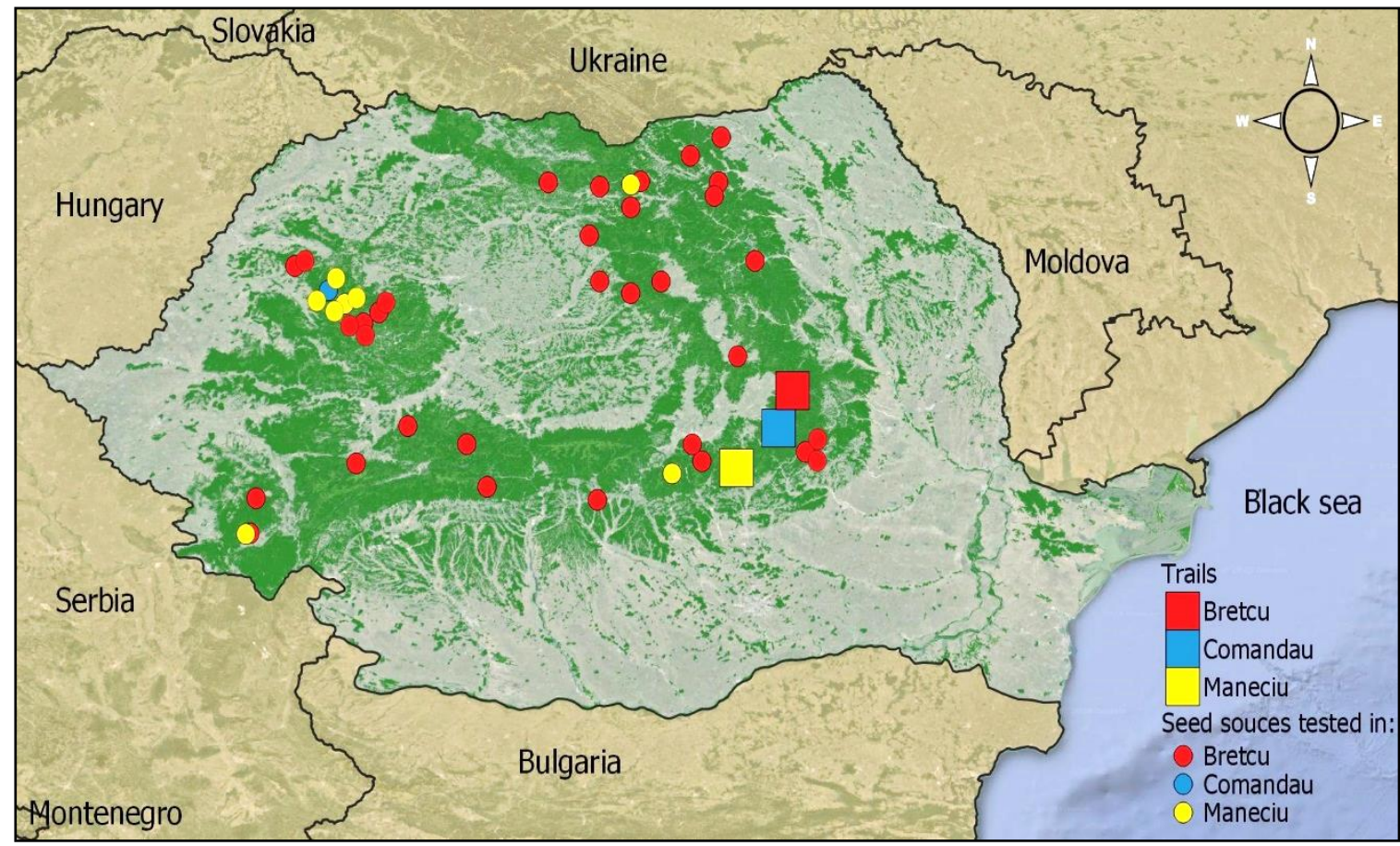

Figure 1. Location of the trials and the tested population's origin.

The Comandău comparative trial was also established in the ecological optimum for Norway spruce, in the Curvature Carpathians region (inner zone of the Carpathian chain), at a 1020-m average altitude (a.s.1.), $45^{\circ} 42^{\prime} \mathrm{N}$ latitude and $26^{\circ} 18^{\prime} \mathrm{E}$ longitude, in mountainous mixed-stand vegetation forest of superior productivity. The slope has a north exposition, and a $16^{\circ}$ inclination; the soil is typical districambosoil. The average annual temperature is $4.8^{\circ} \mathrm{C}$ and the sum of the annual precipitation is $880 \mathrm{~mm}$. The design was incompletely balanced, with 4 replications and 3-9 seedlings per split plot, planted at 2.5 by $2.5 \mathrm{~m}$ spacing, in which the descendants of six families (three pendula and three pyramidalis) obtained through open or controlled pollinated in the Stâna de Vale population (the blue circle, in Figure 1) were present [7]. This trial was installed in order to compare the pendula trees with the normal crown form trees and also the adaptability of the hybrids of the two forms of Norway spruce.

The economic importance of this FGR, conserved ex situ, regarding the utilization of FRM harvested from these were analyzed. The data for $\mathrm{Dbh}, \mathrm{Th}$, and Tv were used to compare the results of the three FGR to the normal local population, and to the national results of Norway spruce of the same ages. The narrow-sense individual heritability $\left(\mathrm{h}_{\mathrm{i}}{ }^{2}\right)$, half-sib family mean heritability $\left(\mathrm{h}_{\mathrm{F}}{ }^{2}\right)$, and genetic gain were determined in the half-sib trial (Măneciu) in order to express genetic inheritance and also the supplementary gain resulted by the selection of seed trees from the most valuable $10 \%$ trees/families of the trial. Heritability was calculated as [38]:

$$
h_{i}^{2}=\frac{\sigma_{A}^{2}}{\sigma_{P h 1}^{2}}=\frac{4 \sigma_{f}^{2}}{\sigma_{f}^{2}+\sigma_{f x r}^{2}+\sigma_{e}^{2}} \quad h_{F}^{2}=\frac{\sigma_{A}^{2}}{\sigma_{P h 2}^{2}}=\frac{\sigma_{f}^{2}}{\sigma_{f}^{2}+\frac{\sigma_{f x r}^{2}}{r}+\frac{\sigma_{e}^{2}}{r x n}}
$$

where $\sigma^{2} \mathrm{~A}$ is the additive genetic variance, $\sigma^{2} \mathrm{Ph}$ is the phenotypic variance, $\sigma_{\mathrm{f}}^{2}$ is the family variance, $\sigma^{2} \mathrm{fxr}$ is the family $\times$ replication interaction variance, $\sigma_{\mathrm{e}}^{2}$ is the residual variance, $r$ is the number of replications, and $n$ is the number of seedlings/plot. In the experiment with half-sib families, $\sigma^{2} \mathrm{~A}=4 \sigma_{\mathrm{f}}^{2}$. 
For the Comandău full-sib trial, heritability was calculated using the following formula:

$$
\mathrm{h}_{\mathrm{A}}^{2}=\frac{2 \sigma_{\mathrm{GCA}}^{2}}{2 \sigma_{\mathrm{GCA}}^{2}+\sigma_{\mathrm{SCA}}^{2}+\sigma_{\mathrm{M}}^{2}+\sigma_{\mathrm{R}}^{2}+\frac{\sigma_{\mathrm{e}}^{2}}{\mathrm{k}}}
$$

where $\sigma^{2} \mathrm{GCA}$ and $\sigma^{2} \mathrm{SCA}$ are the variances of the general and specific combining abilities; and $\sigma^{2}{ }_{\mathrm{M}}, \sigma^{2} \mathrm{R}$, and $\sigma^{2}$ ere the variances attributed to maternal, reciprocal, and environmental effects (error); and $k$ is the number of replications [37].

For the half-sib and full-sib trials, the genetic gain was calculated at $10 \%$ selection intensity, as [39]:

$$
\Delta \mathrm{G}=\mathrm{i} \times \mathrm{h}^{2} \times \sigma_{\mathrm{P}}
$$

where $\mathrm{i}$ is the selection intensity, $\mathrm{h}^{2}$ is the heritability, and $\sigma_{\mathrm{P}}$ is the phenotypic standard deviation.

For the Breţcu trial, seeds were bulked inside the provenance without preserving the maternal identity, so heritability (and implicitly the genetic gain) could not be calculated.

The differences between the average volumes of trees within the three FGRs and the neighboring unimproved populations were transformed into euros, taking into account the average price per cubic meter of wood, fixed by the market price at the last auction organized by the Romanian National Forest Administrator (Romsilva) [40]. In the areas where the three FGRs are established, Norway spruce regeneration is produced artificially through plantations, and price differences in the purchase of seeds are negligible. No additional costs are required for seed procurement (or seedlings), getting seedlings, land preparation, and planting, compared to the utilization of unimproved FRM. In Romania, the average price of 1000 seedlings (aged 2 years) is about $100 €$.

The data were statistically processed using breedR (a genetic package of the $R$ program) [41,42]. The growth model until the end of the rotation period (110 years) was predicted using the Chapman-Richards function [43] and the genetic gain was incorporated in the equation [44]:

$$
\frac{\mathrm{d}}{\mathrm{dt}} \mathrm{W}=\left(\mathrm{A}^{1-\mathrm{m}} \times \mathrm{W}^{\mathrm{m}}-\mathrm{W}\right) \times \mathrm{K},
$$

where $W$ is a dimensional parameter (Dbh, Th, and Tv); $A$ is an asymptotic parameter, a maximum value of the growth variable; and $m$ and $K$ are the parameters associated with catabolism and allometry ( $K$ indicates a change in the growth rate while $m$ indicates changes in the inflection point of the growth curve, respectively, the slope of growth). The growth function was computed using the "robustbase" package in R [42] for the time series of 110 years. Data from Romanian yield tables [34] corresponding to the production class curve were used to continue the data from the trials. Measurements in trails were fitted with data from the yield tables, constructing a prediction of the growth. The uncertainties and errors associated with the grow curve projected are similar with the ones presented in the yield tables [34]. Data for the unimproved neighbor populations were collected and used for comparation.

\section{Results}

\subsection{Breţcu Trial}

The results obtained by the descendants of the 33 provenances of Norway spruce in the Breţcu comparative trial, at 40 years, demonstrated significantly better growth compared to the nearest population that developed in the same plot and in similar environmental conditions. The trial averages were superior, with $13 \% \mathrm{Dbh}, 14 \%$ Th, and $26 \%$ volume/ha (Table 1 ). 
Table 1. Results of growth traits ( \pm standard deviation) registered in the Brețcu trial, the average of the neighbor unimproved population, and the national mean volume/ha of Norway spruce, at age 40.

\begin{tabular}{ccccc}
\hline Breţcu Trial & $\begin{array}{c}\text { Breast Height Diameter } \\
\mathbf{( c m})\end{array}$ & $\begin{array}{c}\text { Trees Height } \\
\mathbf{( m )}\end{array}$ & $\begin{array}{c}\text { Trees Volume } \\
\left(\mathbf{m}^{\mathbf{3}}\right)\end{array}$ & $\begin{array}{c}\text { Volume/Hectare } \\
\left(\mathbf{m}^{\mathbf{3}} \mathbf{/ h a}\right)\end{array}$ \\
\hline Average Breţcu & $24.8 \pm 5.1$ & $21.6 \pm 2.3$ & $0.518 \pm 0.2$ & 474 \\
Best 10\% provenances & $26.6 \pm 5.2$ & $22.7 \pm 2.3$ & $0.617 \pm 0.2$ & - \\
Best 10\% trees & $33.9 \pm 2.1$ & $25.3 \pm 0.8$ & $0.983 \pm 0.1$ & - \\
Local provenance (in trial) & $24.0 \pm 5.3$ & $21.6 \pm 2.3$ & $0.509 \pm 0.2$ & - \\
IUFRO standard provenance & $24.5 \pm 5.2$ & $21.8 \pm 2.3$ & $0.509 \pm 0.2$ & - \\
Nearest population & $22.0 \pm 4.7$ & $19.0 \pm 2.2$ & $0.345 \pm 0.1$ & 375 \\
National average volume/ha* & - & - & - & 342 \\
\hline
\end{tabular}

Note: * Sources: [45].

If we compare the results obtained by the best $10 \%$ provenances and the most valuable $10 \%$ trees in the Brețcu trial with the nearest unimproved population, the differences are much higher and in favor of the trial trees. Within this trial, the provenance closest to the experiment (Comandău) and the I.U.F.R.O. standard provenance (Moldoviţa) registered a $2 \%$ smaller volume compared to the trial average, but when compared with the best performing provenance (Gurghiu), these two are 23\% smaller (Table 1).

In Romania, the average price per cubic meter of Norway spruce wood assortment of $15-30 \mathrm{~cm}$ in diameter is approximatively $34 €[40]$. The economic impact of the utilization of forest reproductive materials from Breţcu FGR translates into a minimum profit of $3366 € /$ ha $(474-375=99 \times 34=3366)$, indicating that it is possible to increase the average volume/ha of the trial to the local population mean volume/ha when the best $10 \%$ trees are selected as seed trees.

\subsection{Măneciu Trial}

In the Măneciu half-sib comparative trial, the same average values $(\mathrm{Dbh}=17.0 \mathrm{~cm}, \mathrm{Th}=16.2 \mathrm{~m}$, $\mathrm{Tv}=0.21 \mathrm{~m}^{3}$ ) were obtained both for the pendula and pyramidalis families, at 25 years. Inside the pendula form, the most performed $10 \%$ families registered an $11 \%$ superiority for Tv compared to the trial average, while, at the individual tree level, the average $\mathrm{Tv}$ of the best $10 \%$ pendula trees ( 96 trees, which will be chosen as seed trees) exceeded with $98 \%$ the trial average.

The nearest Norway spruce stand with the same age and growth in similar environmental conditions presents mean values for Dbh, Th, and $\mathrm{Tv}$ that are inferior by $12 \%, 20 \%$, and $44 \%$, respectively, than the Măneciu average trial. Therefore, the average Tv of the seed trees is 3.5 times larger than the unimproved local population. However, to avoid overestimation, the economic profitability of using FRM from FGRs was calculated using the Măneciu Tv average.

In Romania, the average price per cubic meter of Norway spruce wood assortment of the 10-25 cm diameter is approximatively $25 €$ [40]. The economic impact of the utilization of forest reproductive materials from Măneciu FGR translates into a minimum profit of $2775 € /$ ha $(252-141=111 \times 25=$ $2775)$, reporting the average volume/ha of the trial to the mean volume/ha of the nearest unimproved population. It is possible to increase this by selecting the best $10 \%$ trees as seed trees.

\subsection{Heritability and Genetic Gain in the Măneciu Trial}

In the Măneciu trial, the narrow-sense individual heritability ranged between 0.01 and 0.32 . The highest inheritance rate for mass selection was registered for Th, especially for the pyramidalis trees. For the family selection, the heritability ranged between 0.13 and 0.67 , with the highest inheritance rate also registered for Th, but this time the pendula trees were noticed (Table 2).

For all trees, and also separately for pendula and pyramidalis trees, superior genetic gains were registered for Th when the mass selection was applied. For the family selection, different strategies must be applied: The selection for Th, once again, for pendula, while for pyramidalis trees, the genetic gain values were higher for Dbh. For the pendula trees, the genetic gain was higher at the family 
level, while for pyramidalis trees, the mass selection strategy seems to be more appropriate (Table 2). These data may indicate a selection strategy in favor of the best pendula trees from the top populations regarding Th because of the high inheritance rate (Figure 2).

Table 2. Results of growth traits ( \pm standard deviation), heritability, and genetic gain in the Măneciu trial.

\begin{tabular}{cccc}
\hline Măneciu Trial & Breast Height Diameter & Tree Height & Tree Volume \\
\hline & All trees & & \\
Best 10\% trees* $_{\text {Trial average* }}$ & $22.2 \pm 2.4$ & $19.1 \pm 0.6$ & $0.382 \pm 0.1$ \\
Heritability (i/F) & $17.0 \pm 3.6$ & $16.2 \pm 2.1$ & $0.210 \pm 0.1$ \\
Genetic gain (i/F) (\%) & $0.08 / 0.18$ & $0.23 / 0.31$ & $0.04 / 0.15$ \\
& $15 / 13$ & $25 / 22$ & $13 / 21$ \\
Best 10\% trees* & Pendula trees & & \\
Average pendula* & $22.0 \pm 2.5$ & $19.2 \pm 0.7$ & $0.377 \pm 0.1$ \\
Heritability (i/F) & $17.0 \pm 3.7$ & $16.2 \pm 2.1$ & $0.210 \pm 0.1$ \\
Genetic gain (i/F) $(\%)$ & $0.02 / 0.15$ & $0.23 / 0.67$ & $0.01 / 0.18$ \\
& $2 / 8$ & $20 / 34$ & $2 / 20$ \\
Best 10\% trees* & Pyramidalis trees & & \\
Average pyramidalis* & $22.4 \pm 2.4$ & $19.1 \pm 0.6$ & $0.387 \pm 0.1$ \\
Heritability (i/F) & $17.0 \pm 3.6$ & $16.2 \pm 2.1$ & $0.210 \pm 0.1$ \\
Genetic gain (i/F) $(\%)$ & $0.19 / 0.21$ & $0.32 / 0.13$ & $0.14 / 0.15$ \\
\end{tabular}

Note: * The results are expressed in $\mathrm{cm} / \mathrm{m} / \mathrm{m}^{3}$ for Dbh, Th, and $\mathrm{Tv}$, respectively; (i/F = individual/ family). Genetic gain was calculated for the best $10 \%$ trees/families selected after Th.

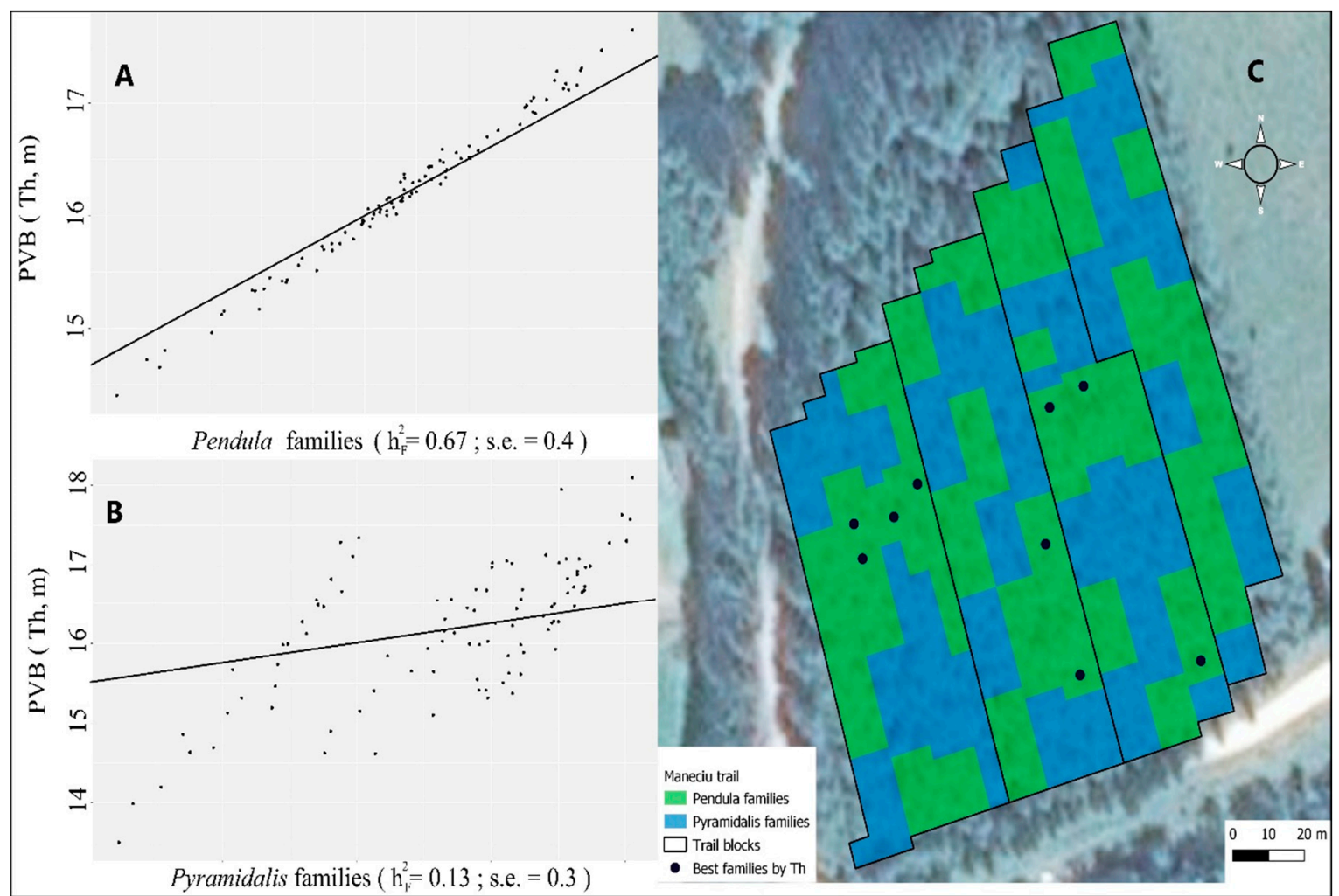

Figure 2. Predicted breeding values (PBVs) for pendula (A) and pyramidalis (B) families, according to Th, and the spatial distribution $(\mathbf{C})$ of the two forms in the Măneciu trial. The most valuable pendula families are dotted.

The influence of the environmental conditions, expressed by the replication effect, is much stronger for the pyramidalis trees although the edge effect, at least, should have equally affected the two forms of Norway spruce and the forms were randomly distributed, as can be seen in Figure 2 (right side). 
Among the best nine pendula families (for Th), four are grouped on a small surface in the first replication, which favors pollination between them.

\subsection{Comandău Trial}

The average Tv value of all 766 trees in the Comandău trial was $0.112 \mathrm{~m}^{3}$; this was driven especially by the hybrids pyramidalis $\times$ pendula $\left(0.14 \mathrm{~m}^{3}\right)$ (Figure 3$)$. The first two trees, hybrids belonging to the combinations $41 \times 7$ and $40 \times 6$ (both pyramidalis $\times$ pendula), recorded values 3.4 times higher than the average of the experiment, showing pronounced positive somatic heterosis. The trial average value for Dbh was $14.1 \mathrm{~cm}$, while for Th, the mean value was $11.6 \mathrm{~m}$, with the best results found in the $\mathrm{N} \times \mathrm{P}$ hybrids. The best-performing 10\% trees, which would be chosen as seed trees, registered a mean Tv 2.3 times larger than the trial average. Depending on the growth traits, the pendula ideotype registered poor results in the Comandău trial.

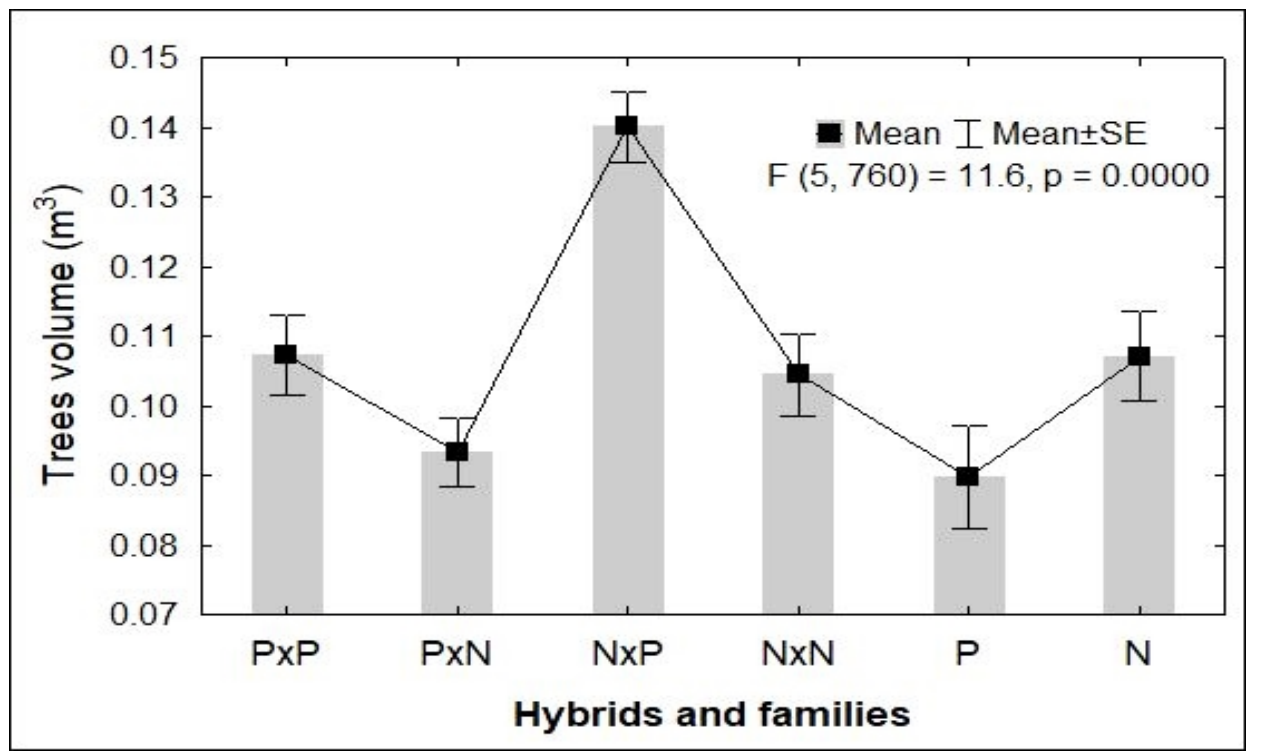

Figure 3. Mean Tv values of pendula (P) and normal (N, pyramidalis) crown forms and their hybrids.

In the nearest comparable population (same plot, age, and similar environmental conditions), the Norway spruce registered average values of $13 \mathrm{~cm}, 10.5 \mathrm{~m}$, and $0.073 \mathrm{~m}^{3}$, for Dbh, Th, and $\mathrm{TV}$, respectively. It is noted that the genetically improved population recorded a $53 \%$ higher $\mathrm{Tv}$ value. The volume per hectare in the Comandău test was $115 \mathrm{~m}^{3}$, while in the unimproved neighbor population, where the planting scheme was denser $(2 \mathrm{~m}$ by $2 \mathrm{~m})$, the volume per hectare was $23 \%$ lower.

In Romania, the average price per cubic meter of the Norway spruce wood assortment $10-18 \mathrm{~cm}$ in diameter is approximatively $20 €$ [40]. The economic impact of the utilization of FRM from Comandău FGR translates into a minimum profit of $540 € /$ ha $(115-88=27 \times 20=540)$, reporting the average volume/ha of the trial to the local unimproved population mean value. It is possible to increase this by selecting the best $10 \%$ as seed trees.

\subsection{Heritability and Genetic Gain in the Comandău Trial}

In the Comandău full-sib trial, heritability and genetic gain were determined first for the hybrids, taking into account the general and specific combining abilities, maternal, reciprocal, and environmental effects. The heritability was zero for Th, while for Dbh and Tv, the heritability was 0.21 and 0.19 , respectively. The genetic gain, calculated at a $10 \%$ selection intensity, was $24 \%$ for Dbh and only $1 \%$ for Tv. In this situation, the breeding strategy should focus on Dbh. Only for the narrow crown trees (with both parents' pendula), at the same selection intensity, the genetic gains were $13 \%$ for $\mathrm{Dbh}$ and $1 \%$ for 
Tv. For a cross-pendula selection, with the unique goal of improving the growth traits, the breeding strategy will also follow the Dbh.

The narrow-sense individual heritability and genetic gain were also determined for the half-sib trees. In this case, the inheritance rate was $0.50,0.24$, and 0.49 for $\mathrm{Dbh}$, Th, and $\mathrm{Tv}$, respectively. The genetic gain at a $10 \%$ selection intensity was $46 \%$ for Dbh, $16 \%$ for Th, and $5 \%$ for Tv. However, this great genetic gain (especially for Dbh) resulted from the selection of the most valuable 15 trees, which would lead to a reduction of genetic diversity. The selection of the most valuable half-sib trees will be incorporated into the individual selection for the entire trial. A cross-pendula selection of the half-sib trees is indicated because the heritability values, $0.58,0.18$, and 0.61 for $\mathrm{Dbh}$, Th, and $\mathrm{Tv}$, respectively, were 4 to 8 times higher than for the pyramidalis trees.

\subsection{Predicting the Growth Model and Profitability at the End of the Rotation Period}

For the Breţcu open-pollinated trials as compared to the closest unimproved population, the results for growth traits at the age of 40 years, combined with the results recorded 10 years earlier, generated a prediction for the end of the rotation period (110 years) with a $28 \%$ superior volume/trees in favor of the Breţcu trial (Figure 4). Between the Măneciu half-sib trial and the closest unimproved population, the difference for the same trait was also favorable for the trial (with $31 \%$ ), while as compared the Comandău full-sib experiment (with its unimproved neighbor population), the superiority of the trial was the lowest at $20 \%$ (Figure 4). This difference is likely to increase after the removal of the additional stems.

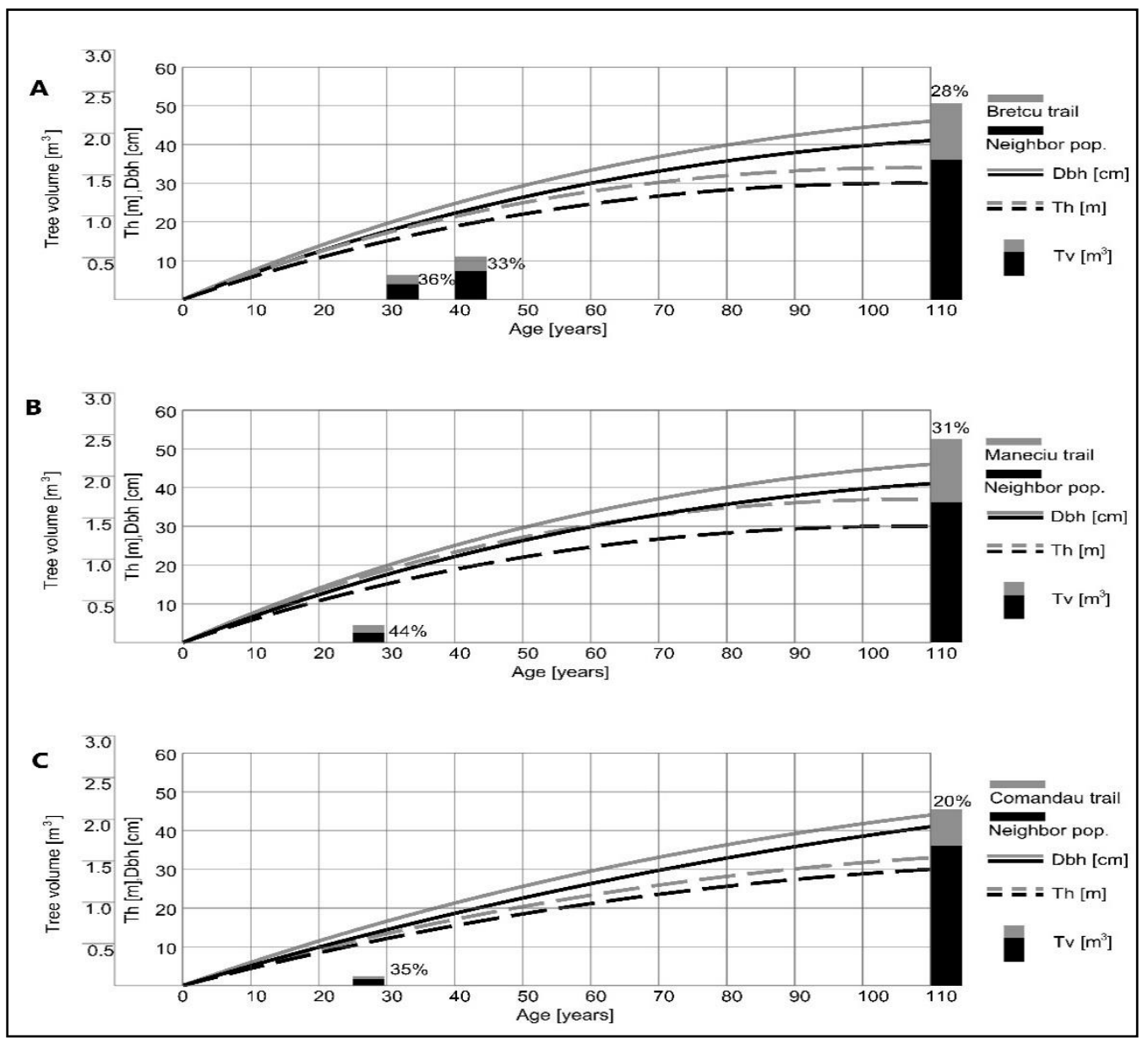

Figure 4. Prediction of the growth model development until the end of the rotation period for Brețcu (A), Măneciu (B) and Comandău (C) trials, compared to their unimproved neighboring populations. 
At the end of the rotation period (trees age of 110 years old), as a product of the tree volume (Tv), an average minimum $20 \%$ profitability could occur, which will generate a minimum of $7560 € /$ ha profitability at an $168 \mathrm{~m}^{3}$ difference in trees volume/ha, an average of 500 trees/ha at age 110 years [34], and an average price per cubic meter of Norway spruce wood assortment of 30-50 cm diameter of about $45 €[40]$.

\section{Discussion}

For forest owners, especially for those with small forest areas, the decision in using improved FRM for afforestation should be based on serious arguments, and careful data about FRM's superior impact on tree growth and wood quality, as well as increasing the resistance of forests to the harmful action of biotic and abiotic factors. A reliable estimate as to the minimum economic profit that could be obtained from the use of FRM from FGR would make their decision easier [44,46]. The results obtained here through comparative trials indicate a high rate of genetic inheritance in the offspring and thus, implicitly, an important genetic gain. This would suggest the use of FRM based on the performance both in the provenance region of the tested populations and also from the trial region where they performed [47]. Further, individual selections can be made in the trials by choosing the most valuable trees as seed trees, depending on the traits followed by the selection.

The tree volume/hectare registered in the Breţcu trial at age 40 years (36\% of a rotation period) was $26 \%$ higher than the nearest unimproved population and the difference increased exponentially if we reported the most valuable $10 \%$ trees (which will be selected as seed trees) to the nearest population. Because the same actions are necessary for afforestation at the end of the rotation period as when using FRM from other seed sources, only small differences in seed costs appear in the economic balance and a minimum profit of $3366 € /$ ha is still expected. At the same time, the administrator of the Breţcu trial can sell seeds all over the country if they harvest separately for each provenance, selecting the most vigorous trees as seed trees.

In the Măneciu half-sib trial, the tree volume/hectare was 79\% higher than the nearest unimproved population at 25 years (almost a quarter of a rotation period), and no differences in growth were registered for narrow and normal crown forms of Norway spruce. A minimum profit of $2775 € /$ ha is predicted and the seeds from the Măneciu trial can be used in $58 \%$ of the Romanian Carpathian provenance regions (if harvested separately for each provenance). However, the different reaction capacity of Norway spruce in changed environmental conditions reported in numerous studies [35,48-51] recommends extreme attention to the movement of FRM. The heritability and genetic gain indicate the possibility of adopting the pendula selection in order to promote this ideotype. A method that combines family selection with mass selection is recommended, by choosing the best pendula trees from the top populations regarding Th because of the high inheritance rate (especially at the family level (0.67)). At the same time, the highest genetic gain (34\%) was shown for pendula trees (according Th), in the case of family selection. The fact that for pendula spruce trees, the genetic gain was higher at the family level than at the tree level, a situation opposite to that recorded for the pyramidalis variety, shows the superior ability of this ideotype to transmit the traits through descent.

The narrow-crowned Norway spruce ideotype (pendula) was not highlighted in the Comandău trial, as in other experiments of the same series [7]. However, its promotion is based on superior resistance to wind and snow [37,52]. In the Comandău trial, the volume/ha was, once again, higher than in the unimproved population $(+31 \%)$. The very significant differences between the results recorded in the Comandău and Măneciu trials, though close in age, are due to the fact that the seedlings planted in Comandău were affected by late frosts in the nursery phase, and by 2018, 33\% of the trees had developed presenting two or even three stems. In the same time, the growth of the Măneciu trial are stunning, with the Th exceeding the upper limit of the Romanian production tables for the 25-year spruce stands [35]. The genetic gain registered an impressive value for $\mathrm{Dbh}(24 \%)$ at a $10 \%$ selection intensity, a value very close to the maximum forecast in Europe [28,53]. 
In the full-sib trial, the genetic gain was highest for Dbh, while in the half-sib experiment, the same parameter registered a superior mean value for Th, which recommends a different selection strategy from the two trials, according to the trait that presented higher inheritance rates. Additionally, the selection in favor of the pendula trees will be a mass selection in the full-sib experiment and a combination of family and mass selection in the half-sib experiment. In the open-pollinated trial, in order to sell seeds all over the country, the selection strategy for Dbh or Th (or maybe Tv) was the same as in the half-sib experiment, by selecting the most vigorous trees as seed trees inside of all 33 provenances, and, after this selection stage, the harvesting and storage of seeds must be done separately in the provenances.

These results led to a rate of profitability, at present, of between 540 and $3366 € /$ ha, a value that is predicted to increase until the end of the rotation period, at which point the genetic gain will generate a profit of at least $7560 € /$ ha. The lowest economic impact $(20 \%$ in Tv) is predicted for the Comandău full-sib experiment, but it is possible that the difference with the neighboring unimproved population grew until the end of the rotation period because the additional stems that affected $33 \%$ of the trees were removed. In Europe, previous research showed a $20 \%$ higher productivity in Norway spruce stands established with seedlings obtained from seed orchards, compared to the productivity of unimproved neighboring stands, and the difference increased in the third generation of selection by up to $35 \%[28,46,53]$. A minimum $20 \%$ profitability benefit that can be increased to $28 \%-31 \%$ (according to the Măneciu and Brețcu tests) was predicted from our research at the end of the rotation period. We modeled different Chapman-Richard growth functions based on the trials and nearest unimproved populations, and a trend developed. However, because we did not have any trial that reached the age of 110 years, these predictions have a significant degree of uncertainty. Nevertheless, the results of this study are in agreement with previous research conducted in Europe.

Climate change is faster than forest tree species' adaptation and current scenarios show that in the context of global warming, with increasing temperatures and decreasing precipitations, forest tree species are likely to migrate north or to a higher altitude [28]. Therefore, we need to take into account the assisted migration of forest tree species, an intentional anthropogenic movement of individuals and populations. In this context, adapted populations need to be ex situ conserved and used for the production of seedlings. In this context, the narrow-crowned Norway spruce ideotype could be used by researchers and professional workers on forest restoration and afforestation activities, in the environmental conditions favorable for Norway spruce, with some of them described in the present study as well as in other previous research $[7,35,37,52]$.

It would be profitable if future research directions reflected a desire to promote the narrow crown Norway spruce ideotype, for which a clonal seed orchard will be established, where a part of the last Romanian pendula spruce populations (which reached 120-160 years old) will be reproduced. Additionally, investigations will continue at the DNA level in order to determine how the character is transmitted. The environmental conditions in which this ideotype developed very well will be more closely investigated to try to determine the importance of the local environmental conditions.

\section{Conclusions}

The growth trait results from three comparative trials, belonging to different breeding levels (open-pollinated, half-sib, and full-sib, the last two being focused on the narrow crown Norway spruce ideotype, pendula form), were superior to the unimproved neighbor populations $(26 \%-79 \%$ for volume/ha) and the differences increased if only the best $10 \%$ seed trees of the trials were used in the evaluation.

For Th, a five times higher family mean heritability was registered for the pendula trees in the half-sib trial, while in the full-sib experiment, the pendula trees (both full and half pendula) again registered higher heritability but for Dbh, which suggests the pendula selection for different traits in the two trials. 
The profitability of using FRM from FGR ranged between 540 and $3366 € /$ ha, a value that is predicted to increase until the end of the rotation period (110 years), when the genetic gain could generate a profit of $7560 € /$ ha.

Author Contributions: Conceptualization, N.M., M.B. and E.N.A.; methodology, M.B. and R.G.R.; software, M.B. and R.G.R.; validation, N.M. and E.N.A; formal analysis, M.B. and R.G.R.; investigation, M.B.; resources, M.B.; data curation, M.B. and E.N.A.; writing-original draft preparation, M.B.; writing-review and editing, N.M. and E.N.A.; visualization, E.N.A.; supervision, N.M.; project administration, M.B.; funding acquisition, M.B. All authors have read and agreed to the published version of the manuscript.

Funding: This paper was financed by the Romanian Ministry of Education and Research, in the frame of Nucleu Programme contracted with National Institute for Research and Development in Forestry "Marin Drăcea" (Project PN19070302).

Conflicts of Interest: The authors declare no conflict of interest.

\section{References}

1. White, T.W.; Adams, W.T.; Neale, D.B. Forest Genetics; CABI Publishing: Cambridge, UK, 2007; p. 682.

2. Cavatassi, R. Valuation Methods for Environmental Benefits in Forestry and Watershed Investment Projects. ESA Working Paper No. 04-01. Available online: http://www.fao.org/3/ae056e/ae056e00.pdf (accessed on 3 February 2020).

3. Dong, P.-W.; Zhuang, S.-Y.; Lin, X.-H.; Zhang, X.-Z. Economic evaluation of forestry industry based on ecosystem coupling. Math. Comput. Model. 2013, 58, 1010-1017. [CrossRef]

4. Routa, J.; Kellomäki, S.; Strandman, H.; Bergh, J.; Pulkkinen, P.; Peltola, H. The timber and energy biomass potential of intensively managed cloned Norway spruce stands. GCB Bioenergy 2013, 5, 43-52. [CrossRef]

5. Pyörälä, P.; Peltola, H.; Strandman, H.; Kilpeläinen, A.; Asikainen, A.; Jylhä, K.; Kellomäki, S. Effects of management on economic profitability of forest biomass production and carbon neutrality of bioenergy use in Norway spruce stands under the changing climate. Bioenergy Res. 2014, 7, 279-294. [CrossRef]

6. Kilpeläinen, A.; Alam, A.; Torssonen, P.; Ruusuvuori, H.; Kellomäki, S.; Peltola, H. Effects of intensive forest management on net climate impact of energy biomass utilisation from final felling of Norway spruce. Biomass Bioenergy 2016, 87, 1-8. [CrossRef]

7. Budeanu, M.; Apostol, E.N.; Popescu, F.; Postolache, D.; Ioniţă, L. Testing of the narrow crowned Norway spruce ideotype (Picea abies f. pendula) and the hybrids with normal crown form (pyramidalis) in multisite comparative trials. Sci. Total Environ. 2019, 689, 980-990. [CrossRef] [PubMed]

8. Savolainen, O.; Bokma, F.; García-Gil, R.; Komulainen, P.; Repo, T. Genetic variation in cessation of growth and frost hardiness and consequences for adaptation of Pinus sylvestris to climate change. For. Ecol. Manag. 2004, 197, 79-89. [CrossRef]

9. Lindgren, D.; Karlsson, B.; Andersson, B.; Prescher, F. The Swedish Seed Orchard Program for Scots Pine and Norway Spruce. In Proceedings of the a Seed Orchard Conference, Umea, Sweden, 26-28 September 2007; Lindgren, D., Ed.; pp. 142-151. Available online: http://daglindgren.upsc.se/Umea07/ZProcFinalFeb08.pdf (accessed on 14 February 2020).

10. Koskela, J.; Vinceti, B.; Dvorak, W. The Use and Exchange of Forest Genetic Resources for Food and Agriculture; Backround study paper No 44; Commission on Genetic Resources for Food and Agriculture Organization of the United Nations: Rome, Italy, 2010; p. 72. Available online: http://citeseerx.ist.psu.edu/viewdoc/ download?doi=10.1.1.604.5162\&rep=rep1\&type=pdf (accessed on 14 February 2020).

11. Pâques, L.E. Introduction. In Forest Tree Breeding in Europe. Current State-of-the-Art and Perspectives, Managing Forest Ecosystems, 1st ed.; Pâques, L.E., Ed.; Springer: Dordrecht, The Netherlands; Berlin/Heidelberg, Germany; New York, NY, USA; London, UK, 2013; pp. 1-9. [CrossRef]

12. Ruotsalainen, S. Increased forest production through forest tree breeding. Scand. J. For. Res. 2014, $29,333-344$. [CrossRef]

13. Dumroese, R.K.; Williams, M.I.; Stanturf, J.A.; St Clair, J.B. Considerations for restoring temperate forests of tomorrow: Forest restoration, assisted migration, and bioengineering. New For. 2015, 46, 947-964. [CrossRef]

14. Frank, A.; Sperisen, C.; Howe, G.T.; Brang, P.; Walthert, L.; St Clair, B.J.; Heiri, C. Distinct genecological patterns in seedlings of Norway spruce and silver fir from a mountainous landscape. Ecology 2017, 98, 211-227. [CrossRef] 
15. Frank, A.; Howe, G.T.; Sperisen, C.; Brang, P.; St Clair, J.B.; Schmatz, D.R.; Heiri, C. Risk of genetic maladaptation due to climate change in three major European tree species. Glob. Chang. Biol. 2017, 23, 5358-5371. [CrossRef]

16. Myking, T.; Rusanen, M.; Steffenrem, A.; Kjær, E.D.; Jansson, G. Historic transfer of forest reproductive material in the Nordic region: Drivers, scale and implications. Forestry 2016, 89, 325-337. [CrossRef]

17. Forest Europe. State of Europe's Forests. 2015. Available online: http://www.foresteurope.org/docs/ fullsoef2015.pdf (accessed on 14 February 2020).

18. Leech, S.M.; Lara Almuedo, P.; O’Neill, G. Assisted migration: Adapting forest management to a changing climate. BC J. Ecosyst. Manag. 2011, 12, 18-34. Available online: https://jem-online.org/index.php/jem/article/ view/91/98 (accessed on 18 February 2020).

19. Liesebach, M. Variety transfer across Europe. In Forest Tree Breeding in Europe; Current State-of-the-Art and Perspectives, 1st ed.; Pâques, L.E., Ed.; Springer: Dordrecht, The Netherlands; Berlin/Heidelberg, Germany; New York, NY, USA; London, UK, 2013; pp. 75-77. [CrossRef]

20. Aarrestad, P.A.; Myking, T.; Stabbetorp, O.E.; Tollesfrud, M.M. Foreign Norway Spruce (Picea abies) Provenances in Norway and Effects on Biodiversity. Nina Report 1075. 2014. Available online: NINArapport1075_171014_kvalitetssikret.docx (accessed on 18 February 2020).

21. Rehfeldt, G.E.; Jaquish, B.C.; Sáenz-Romero, C.; Joyce, D.G.; Leites, L.P.; St Clair, J.B.; López-Upton, J. Comparative genetic responses to climate in the varieties of Pinus ponderosa and Pseudotsuga menziesii: Reforestation. For. Ecol. Manag. 2014, 324, 147-157. [CrossRef]

22. Jansen, S.; Geburek, T. Historic translocations of European larch (Larix decidua Mill.) genetic resources across Europe-A review from the 17th until the mid-20th century. For. Ecol. Manag. 2016, 379, 114-123. [CrossRef]

23. Jansen, S.; Konrad, H.; Geburek, T. Crossing borders-European forest reproductive material moving in trade. J. Environ. Manag. 2019, 233, 308-320. [CrossRef]

24. Lefèvre, F.; Koskela, J.; Hubert, J.; Kraigher, H.; Longauer, R.; Olrik, D.C.; Schler, S.; Bozzano, M.; Alizoti, P.; Bakys, R. Dynamic Conservation of Forest Genetic Resources in 33 European Countries. Conserv. Biol. 2013, 27, 373-384. [CrossRef]

25. Koskela, J.; Lefèvre, F.; Schueler, S.; Kraigher, H.; Olrik, D.C.; Hubert, J.; Longauer, R.; Bozzano, M.; Yrjn, L.; Alizoti, P. Translating conservation genetics into management: Pan-European minimum requirements for dynamic conservation units of forest tree genetic diversity. Biol. Conserv. 2013, 157, 39-49. [CrossRef]

26. Nystedt, B.; Street, N.R.; Wetterbom, A.; Zuccolo, A.; Lin, Y.C.; Scofield, D.G.; Vezzi, F.; Delhomme, N.; Giacomello, S.; Alexeyenko, A. The Norway spruce genome sequence and conifer genome evlution. Nature 2013, 497, 579-584. [CrossRef]

27. Dean, J.F.D. Future prospects. In Genetics, Genomics and Breeding of Conifers; Plomion, C., Bousquet, J., Kole, C., Eds.; CRC Press: Abingdon, UK, 2011; pp. 404-438.

28. Mullin, T.J.; Andersson, B.; Bastien, J.C.; Beaulieu, J.; Burdon, R.D.; Dvorak, W.S.; King, J.N.; Kondo, T.; Krakowski, J.; Lee, S.J. Economic importance, breeding objectives and achievements. In Genetics, Genomics and Breeding of Conifers; Plomion, C., Bousquet, J., Kole, C., Eds.; CRC Press: Abingdon, UK, 2011; pp. 40-127.

29. Şofletea, N.; Curtu, A.L. Dendrologie (Dendrology); Transylvania University Publishing House: Brasov, Romania, 2007; p. 540.

30. Skrøppa, T. EUFORGEN Technical Guidelines for Genetic Conservation and Use of Norway Spruce (Picea abies); International Plant Genetic Institutes: Rome, Italy, 2003; p. 6. Available online: https://books.google.ro/books (accessed on 19 February 2020).

31. Westin, J.; Haapanen, M. Norway spruce-Picea abies (L.) Karst. In Best Practice for Tree Breeding in Europe; Mullin, T.J., Lee, S.J., Eds.; Skogforsk: Uppsala, Sweden, 2013; pp. $29-47$.

32. Şofletea, N.; Budeanu, M. Response of Norway Spruce (Picea abies (L) Karst.) seed stand progenies tested under different site conditions. Sumar. List 2015, 139, 47-57. Available online: https://hrcak.srce.hr/137362 (accessed on 19 February 2020).

33. Enescu, V.; Ioniţă, L. Inter and intrapopulational genetic variation of some genetic resources of Norway spruce (Picea abies (L) Karst.). Ann. For. Res. 2002, 45, 67-77.

34. Giurgiu, V.; Decei, I.; Drăghiciu, D. Metode Si Tabele Dendrometrice (Methods and Dendrometrical Tables); Ceres Publishing House: Bucharest, Romania, 2004; p. 575. 
35. Apostol, E.N.; Budeanu, M. Adaptability of narrow-crowned Norway spruce ideotype (Picea abies (L.) Karst. pendula form) in 25 years half-sib comparative trials in the eastern Carpathians. Forests 2019, 10, 395. [CrossRef]

36. Pulkkinen, P.; Pöykkö, T. Inherited narrow crown form, harvest index and stem biomass production in Norway spruce, Picea abies. Tree Physiol. 1990, 6, 381-391. [CrossRef] [PubMed]

37. Pârnuţă, G. Variabilitatea Genetică Si Ameliorarea Arborilor De Molid Cu Coroană Îngustă În România (Genetic Variability and Breeding of Narrow-Crowned Norway Spruce Trees in Romania); Silvică Publishing House: Bucharest, Romania, 2008; p. 181, (In Romanian with English Abstract).

38. Nanson, A. Génétique Et Amélioration Des Arbres Forestières (Genetic and Forest Trees Breeding); Les presses agronomique de Gembloux: Gembloux, Belgium, 2004; p. 712. (In French)

39. Falconer, D.S. Introduction to Quantitative Genetics, 2nd ed.; Longmans Green: London, UK; New York, NY, USA, 1981.

40. Fordaq Romania. The Average Price of Wood in Romania. 2019. Available online: https://lemn.fordaq.com/ news/Analiza_Rezultatele_licitatiilor_organizate_de_64951.html (accessed on 12 February 2020).

41. Breed, R. An Open Statistical Package to Analyse Genetic Data (WP6). 2016. Available online: http: //famuvie.github.io/breedR/ (accessed on 3 February 2020).

42. R Core Team. R: A Language and Environment for Statistical Computing; R Foundation for Statistical Computing: Vienna, Austria, 2017; Available online: https://www.R-project.org/ (accessed on 3 February 2020).

43. Richards, F.J. A flexible growth function for empirical use. J. Exp. Bot. 1959, 10, 290-300. [CrossRef]

44. Ahtikoski, A.; Ojansuu, R.; Haapanen, M.; Hynynen, J.; Kärkkäinen, K. Financial performance of using genetically improved regeneration material of Scots pine (Pinus sylvestris L.) in Finland. New For. 2012, 43, 335-348. [CrossRef]

45. Ciceu, A.; Radu, R.; Garcia-Duro, J. National forestry accounting plan of Romania. Voluntari, Romania. 2019. Available online: http://www.mmediu.ro (accessed on 3 February 2020).

46. Rosvall, O. The economic value of tree improvement. In Review of the Swedish Tree Breeding Programme; Rosvall., O., Ed.; Skogforsk: Uppsala, Sweden, 2011; pp. 13-14.

47. Gould, P.; Marshall, D. Incorporation of genetic gain into growth projections of Douglas-fir using ORGANON and the forest vegetation simulator. West. J. Appl. For. 2010, 25, 55-61. [CrossRef]

48. Moberg, L. Predicting knot properties of Picea abies and Pinus sylvestris from generic tree descriptors. Scand. J. For. Res. 2006, 21, 49-62. [CrossRef]

49. Kantola, A.; Mäkinen, H.; Mäkelä, A. Stem form and branchiness of Norway spruce as a sawn timber-Predicted by a process based model. For. Ecol. Manag. 2007, 241, 209-222. [CrossRef]

50. Barszcz, A.; Sandalak, A.; Sandalak, J. Knottiness of spruce stems from the Dolomites as the basis for distinguishing quality zones in round wood. Folia For. Pol. Ser. A 2010, 52, 89-97.

51. Charru, M.; Seynave, I.; Hervé, J.C.; Bontemps, J.D. Spatial patterns of historical growth changes in Norway spruce across western European mountains and the key effect of climate warming. Trees 2014, 28, 205-221. [CrossRef]

52. Zubizarreta Gerendiain, A.; Peltola, H.; Pulkkinen, P. Growth and wood property traits in narrow crowned Norway spruce (Picea abies f. pendula) clones grown in southern Finland. Silva Fenn. 2009, 43, 369-382. [CrossRef]

53. Rosvall, O.; Jansson, G.; Andersson, B.; Ericsson, T.; Karlsson, B.; Sonesson, J.; Stener, L.G. Predicted Genetic Gain from Existing and Future Seed Orchards and Clone Mixes in Sweden. In Proceedings of the Integrating Tree Breeding and Forestry-Proceedings of the Nordic Group for Management of Genetic Resources of Trees, Helsinki, Finland, 23-27 March 2002; Haapanen, M., Mikola, J., Eds.; Research Papers 842. pp. 71-85. Available online: http://urn.fi/URN:ISBN:951-40-1822-2 (accessed on 19 February 2020).

(C) 2020 by the authors. Licensee MDPI, Basel, Switzerland. This article is an open access article distributed under the terms and conditions of the Creative Commons Attribution (CC BY) license (http://creativecommons.org/licenses/by/4.0/). 